\title{
Small Scale Field Experiment on Breaking Wave Pressure on Vertical Breakwaters
}

\author{
Paolo Boccotti, Vincenzo Fiamma, Giuseppe Barbaro, Luigi Collia \\ DICEAM Department, Natural Ocean Engineering Laboratory, Mediterranea University, Reggio Calabria, Italy \\ Email: boccotti@unirc.it, vincenzo.fiamma@unirc.it, giuseppe.barbaro@unirc.it, luigi.collia@carabinieri.it
}

Received 2 August 2015; accepted 13 October 2015; published 16 October 2015

Copyright (C) 2015 by authors and Scientific Research Publishing Inc.

This work is licensed under the Creative Commons Attribution International License (CC BY). http://creativecommons.org/licenses/by/4.0/

c) (i) 0pen Access

\begin{abstract}
A small scale field experiment (SSFE) was performed on vertical breakwaters in the surf zone. The following are some of the findings. Wind seas may yield breaking wave pressure notwithstanding some large deepwater wave steepness, and small elevation of the wall above the mean water level. Caisson breakwaters can withstand some exceptionally high impulsive force peaks (even twice the weight in still water); whereas, with the same sea state and weight, a breakwater composed of layers of solid concrete blocks is destroyed.
\end{abstract}

\section{Keywords}

Impulsive Breaking Wave Pressure, Vertical Breakwater, Small Scale Field Experiment, Breakwater Failure

\section{Introduction}

A small scale field experiment (SSFE) is an experiment performed like in a big wave tank, in sea areas or lakes where wind seas have some small sizes [1]. The paper shows the results of a SSFE on vertical breakwaters in the surf zone.

It is well-known since [2] that, under the action of breaking waves, a vertical breakwater may be subject to pressure peaks of high intensity and short duration. These are called impulsive breaking wave pressures (IBWP).

A first item of the SSFE was to test the questionnaire of [3] for the risk of occurrence of IBWP.

A second item was to analyze resistance or failure of breakwaters under breaking waves. Many tests have been made on this subject on wave flumes [4]. A novelty of this paper is that two vertical breakwaters with a different configuration are beaten by the same wind sea. The interest is in the fact that, notwithstanding the configurations of the two breakwaters is similar to each other, one fully collapses and the other perfectly resists. Realizing the reason for this seeming paradox enables us to choose the more effective configuration in the pre- 
liminary design of a breakwater.

\section{Method}

The experiment was performed off the shore of the NOEL (Natural Ocean Engineering Laboratory) on the Eastern coast of the Straits of Messina. A vertical breakwater was made with concrete blocks (Figure 1). In a configuration $\mathrm{A}$ the blocks were pressed together by some tensioned iron cables so as to obtain a compact structure like that of a caisson breakwater; in a configuration B the blocks were not pressed together. The central section

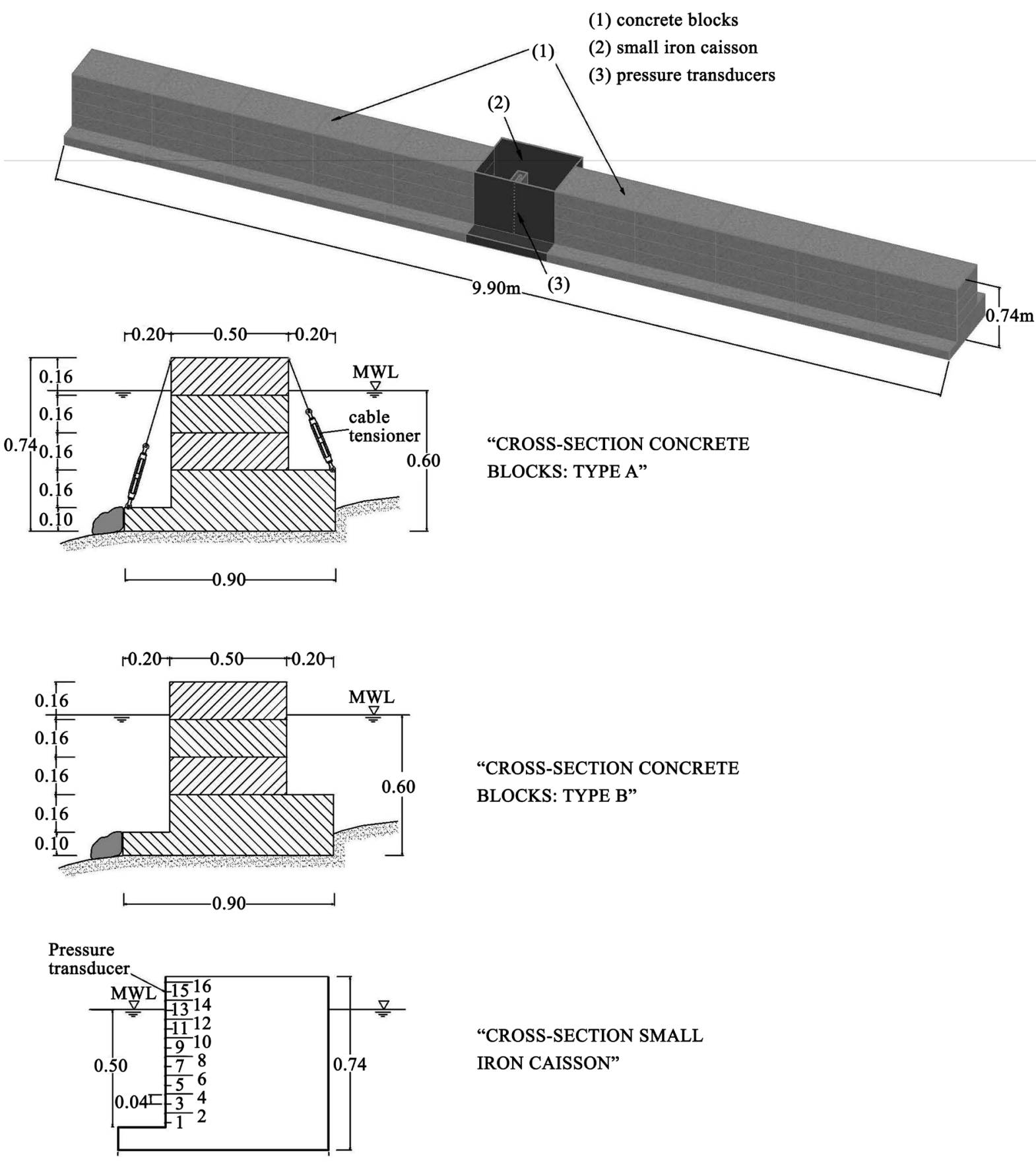

Figure 1. The breakwater of the SSFE. In a stage of the experiment the cross-section had the configuration A. In another stage the cross-section had the configuration B. 
consisted of a small iron caisson being ballasted with pig-iron and equipped with 16 pressure transducers. The incident waves were recorded by an ultrasonic wave probe on deep water. The sample rate was of $100 \mathrm{~Hz}$. Each record had a duration of five-minutes. The average water depth at the base of the upright section was of $0.5 \mathrm{~m}$, and the average depth of the seabed at the breakwater was of $0.6 \mathrm{~m}$ (see Figure 1). The bottom slope was 1/10. The tide amplitude was about $0.15 \mathrm{~m}$.

The period $T_{h}$ of the largest waves of a sea state was obtained from the autocovariance $\Psi(T)$ of the free surface displacement on deep water [1] [5]; the period $T_{1 / 3}$ mean of the wave periods of the largest one third waves of a sea state was obtained from the record of the waves on deep water. The average difference $\left|T_{h}-T_{1 / 3}\right|$ proved to be within the $1.8 \%$ of $T_{h}$. The narrow bandedness parameter $\Psi^{*}$ was obtained from $\Psi(T)$ [1] [5]. The wave force $F$ on the central upright section of the breakwater, proceeded from the difference between the actual sectional force obtained from the measurements of the 16 pressure transducers, and the hydrostatic sectional force. The wave pressure pw was obtained as the difference between the actual pressure on the wall and the hydrostatic pressure. The tide level (being necessary to estimate the water depth and hence the hydrostatic pressures and the hydrostatic sectional force) was estimated from the measurement of the free surface displacement made by the ultrasonic probe on deep water.

\section{Results}

With breakwater A, we obtained 24 five-minute records of wind seas. These had the following characteristics:

$$
\begin{gathered}
0.45 \mathrm{~m}<d<0.52 \mathrm{~m} \\
0.41 \mathrm{~m}<H_{s 0}<0.52 \mathrm{~m} \\
0.25<W / H_{s 0}<0.40 \\
0.60<\psi^{*}<0.70 \\
2.27 \mathrm{~s}<T_{h}<2.56 \mathrm{~s} \\
2.45 \mathrm{~s}<T_{p}<3.10 \mathrm{~s} \\
0.043<H_{s 0} / L_{p 0}<0.056
\end{gathered}
$$

The spectra on deep water were the classic ones of wind seas (see a few examples on Figure 2). These wind seas were superimposed on a very small swell component (see the small peak of the spectrum on about $0.13 \mathrm{~Hz}$ ).

The dominant direction of wind seas on deep water off the beach at Reggio Calabria makes an angle within $25^{\circ}$ with the orthogonal to the contour lines (this has been confirmed by a lot of small scale field experiments [1] [5]). Hence the angle between the dominant wave direction and the orthogonal to the breakwater was definitely smaller than $25^{\circ}$, because of refraction.

Let us consider the questionnaire [3], on the danger of IBWP. We are dealing with a case of rubble mound sufficiently small to be considered negligible. The angle between the wave direction and the line normal to the breakwater is less than $20^{\circ}$. The sea bottom slope $(1 / 10)$ is steeper than $1 / 50$. The breaking point of the progressive wave (in absence of the structure) is located only slightly in front of the breakwater. All of this is proper for the occurrence of IBWP. However there are two conditions which, on the basis of the aforesaid questionnaire, let us conclude that there should be little danger of IBWP; these are

1) a large wave steepness;

2) a small crest elevation that allows much overtopping.

Thus finding IBWP in these wave records was an unexpected outcome of the experiment. This finding is evident in Figure 3, Figure 4 and Figure 5 which show the three largest sectional wave forces $F$ in the 24 records. Each figure shows the pressure distribution $p_{w} /\left(\gamma H_{s 0}\right)$ at the time instant of the maximum sectional wave force, and $F(t)$. We see that the largest values of $p_{w}$ exceed $6\left(\gamma H_{s 0}\right)$.

Breakwater A was able to withstand, without sliding, a $F_{\max }$ of $13.5 \mathrm{kN} / \mathrm{m}$ (see Figure 3) which is twice the $P^{*}$ ! On the opposite, breakwater B after 45 minutes of wind seas very similar to the wind seas that attacked breakwater A, was destroyed (see Figure 6). Only the small iron caisson with the transducers remained stable. In all, the 45 minutes in which breakwater B was destroyed included 9 five-minute records whose characteristics were as follows 


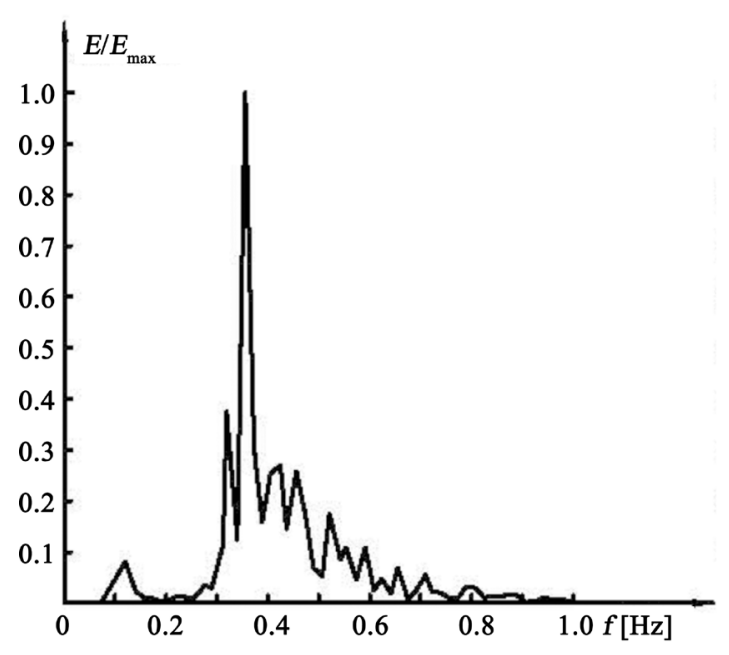

(a)

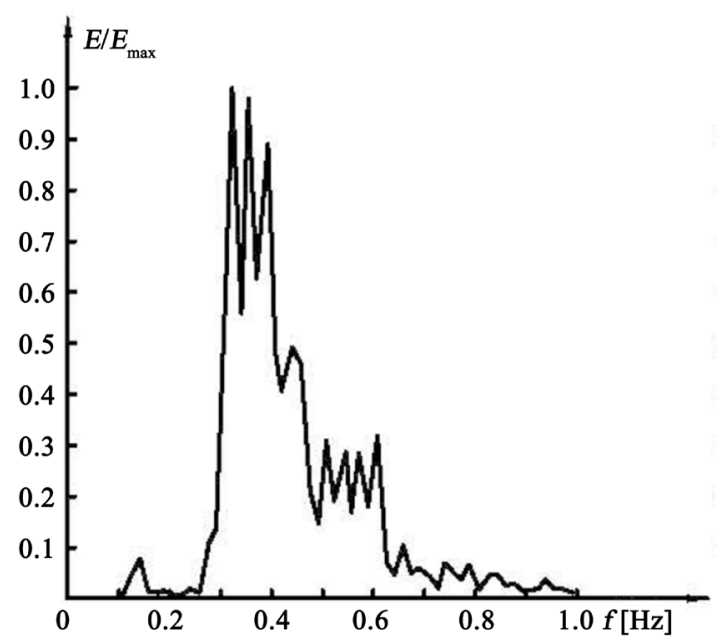

(b)

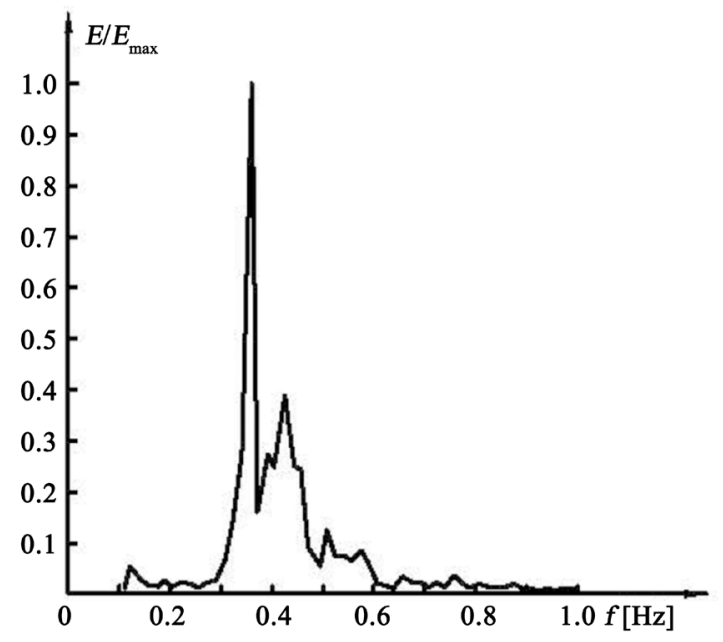

(c)

Figure 2. Frequency spectra of deep water waves: (a) rec. 1373; (b) rec. 1424; (c) rec. 1390.
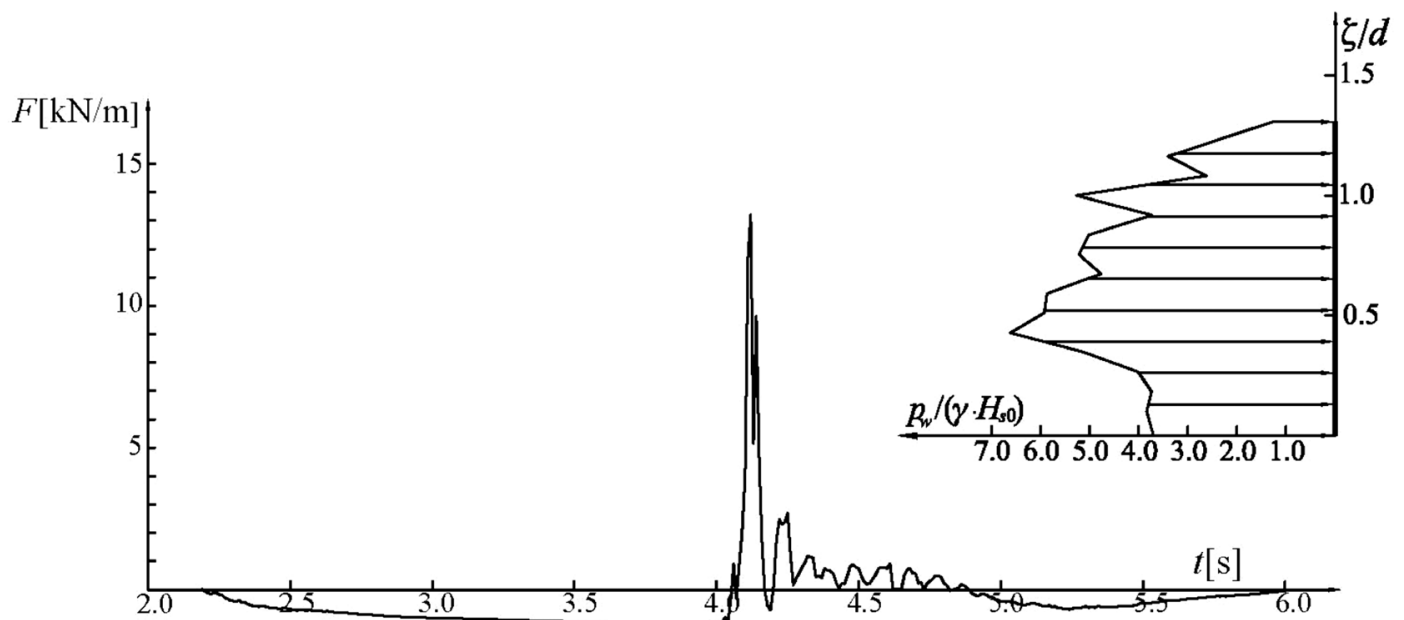

Figure 3. Time history of the largest sectional force, and distribution of the wave pressure yielding the force peak. Breakwater A, rec. 1373. 


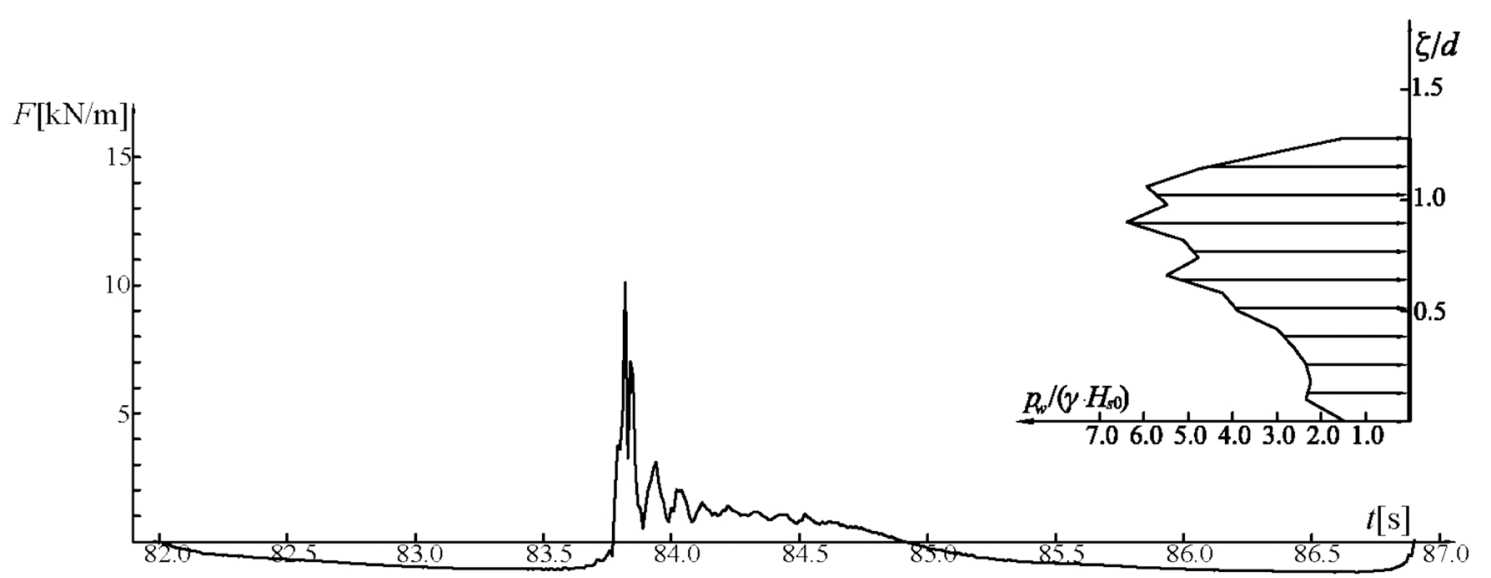

Figure 4. Time history of the second largest sectional force, and distribution of the wave pressure yielding the force peak. Breakwater A, rec. 1427.

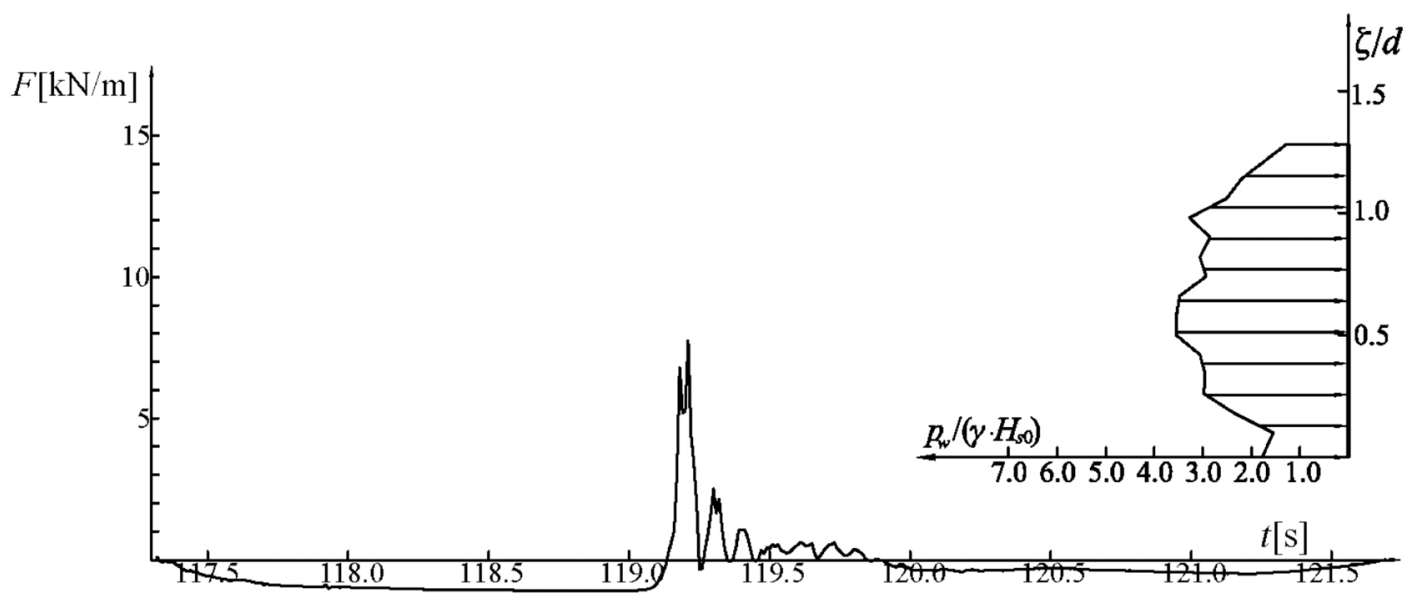

Figure 5. Time history of the third largest sectional force, and distribution of the wave pressure yielding the force peak. Breakwater A, rec. 1390.

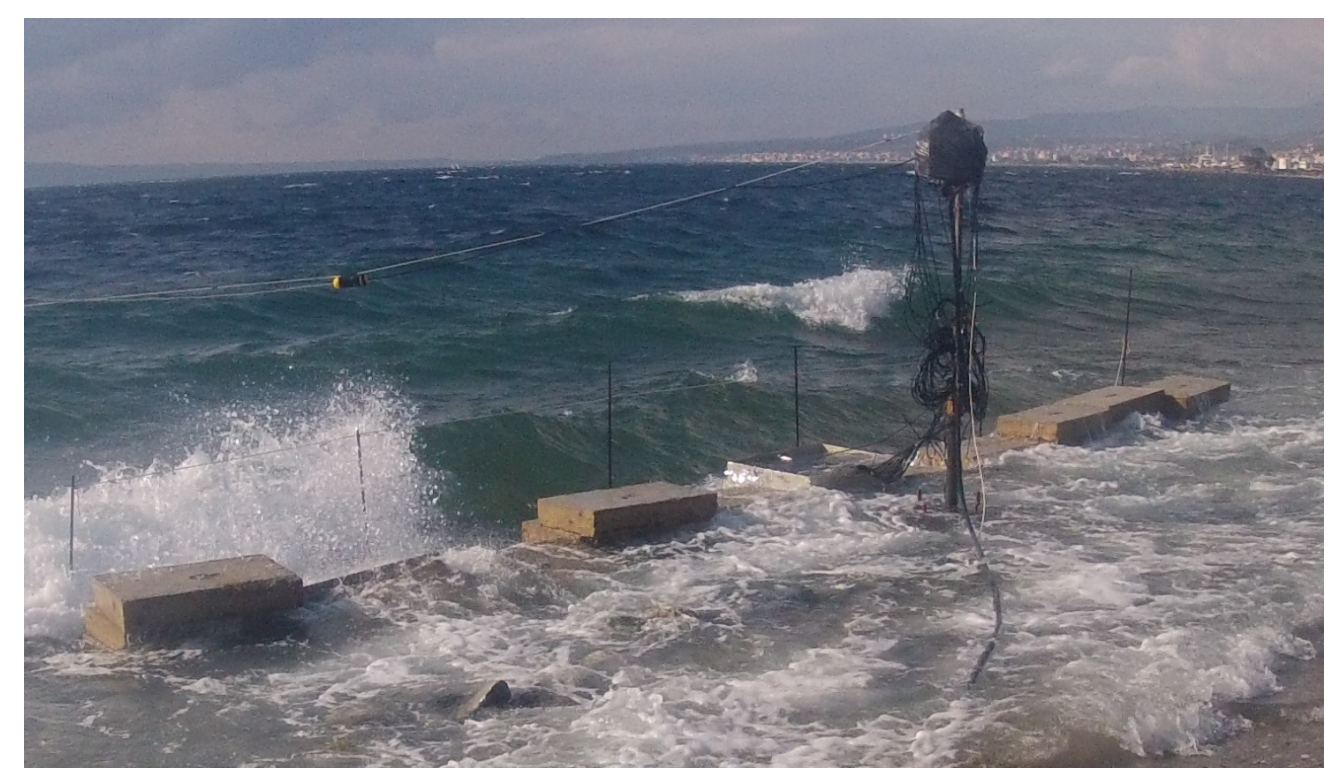

Figure 6. Breakwater B destroyed after 45 minutes of wind seas with the characteristics (8 - 14). 


$$
\begin{gathered}
0.52 \mathrm{~m}<d<0.53 \mathrm{~m} \\
0.40 \mathrm{~m}<H_{s 0}<0.56 \mathrm{~m} \\
0.21<W / H_{s 0}<0.28 \\
0.57<\psi^{*}<0.71 \\
2.36 \mathrm{~s}<T_{h}<2.79 \mathrm{~s} \\
2.45 \mathrm{~s}<T_{p}<3.10 \mathrm{~s} \\
0.040<H_{\mathrm{s} 0} / L_{p 0}<0.051
\end{gathered}
$$

As said these characteristics were close to the characteristics (Equations (1)-(7)) of the wind seas that attacked breakwater A.

Figure 7 shows the time history of the largest sectional wave force recorded on breakwater B. Notwithstanding the sea state is very similar to that of the 24 records with configuration A, the wave force proves to be markedly smaller than that recorded with configuration A (compare Figure 7 with Figure 3, Figure 4 and Figure 5). The fact that the vertical wall was being destroyed (many concrete blocks were displaced from their original location) could be a cause for the wave pressure being less intense.

\section{Analysis of Resistance/Failure}

The horizontal displacement of a section of the breakwater is estimated by numerical integration of the equations:

$$
\begin{gathered}
s_{y_{i+1}}=s_{y_{i}}+0.5\left(v_{y_{i}}+v_{y_{i+1}}\right) \Delta t \\
v_{y_{i+1}}=\operatorname{Max}\left(0, v_{y_{i}}+0.5\left(a_{y_{i}}+a_{y_{i+1}}\right) \Delta t\right)
\end{gathered}
$$

where $i=1,2,3, \cdots$ denotes a sample instant and $a_{y_{i}}$ is estimated by means of:

$$
a_{y_{i}}=\left(F_{i}-\mu R_{V_{i}}-R_{p}\right) /\left(M+C_{i n}\left(M-P^{*} / g\right)\right)
$$

The breakwater slides whenever $a_{y}$ gets greater than zero. This occurs when the horizontal wave force $F$ exceeds the resistance of the soil which is the sum of the friction force exerted on the base of the breakwater $\left(\mu R_{v}\right)$ and the normal force exerted on the rear wall $\left(R_{p}\right)$.

Let us apply these equations in order to realize how breakwater A was able to withstand the wind seas with a

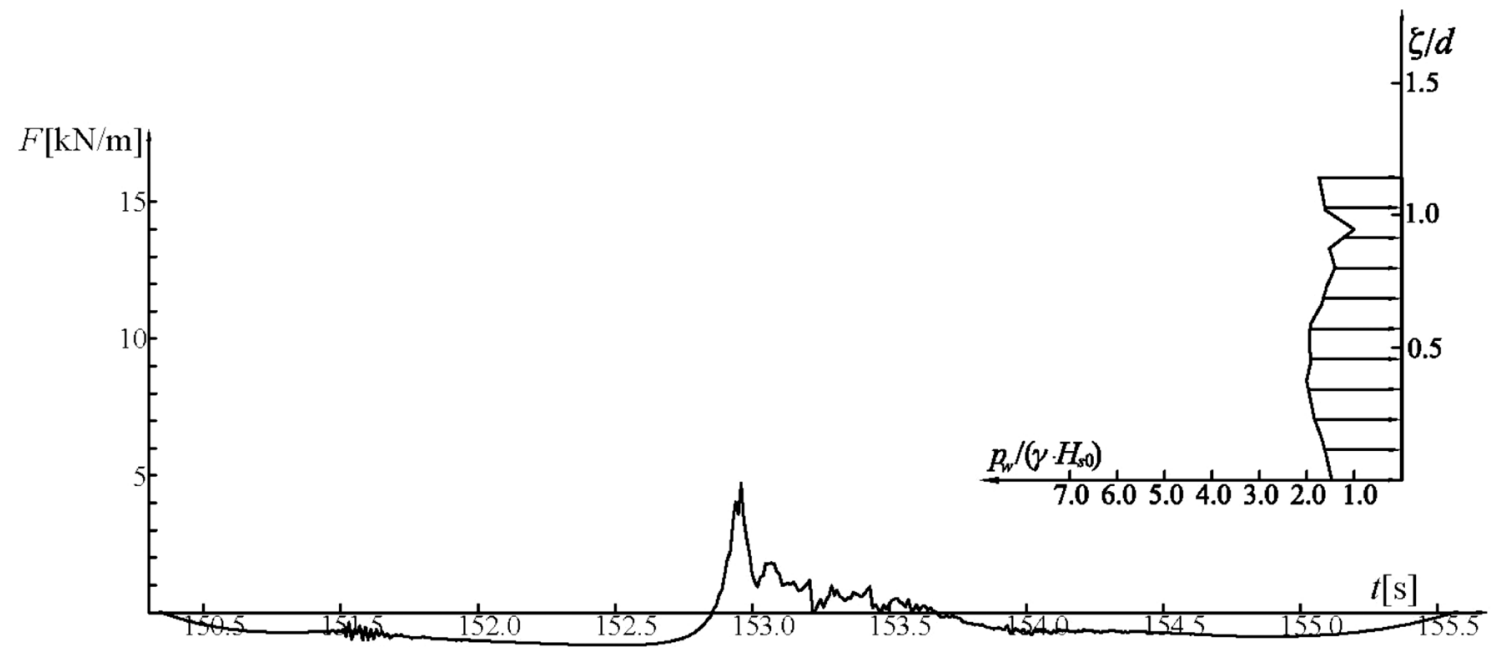

Figure 7. Time history of the largest sectional force (and distribution of the wave pressure yielding the force peak) during the 45 minutes in which breakwater B was broken down by waves. 
$F_{\max }$ twice the $P^{*}$. To this end we firstly consider only the action exerted by waves on the upright section (that is we neglect the uplift force). With $\mu=0.6, C_{i n}=2.0$ and $\phi=40^{\circ}$ ( $\phi$ serves to estimate the passive thrust of the sloping soil) and with the time series data of $F(t)$ of the 24 records, Equations (15)-(17) yield 21 small slides giving a cumulative total displacement of $0.020 \mathrm{~m}$.

The fact that the expected displacement was very small notwithstanding the $F_{\max }$ was twice the $P^{*}$ is due to the very short duration of the IBWP. The fact that the actual displacement was even smaller (we did not observe any displacement) cannot be attributed to the friction factor: with a $\mu$ of 0.65 instead of 0.60 , the displacement would be reduced only from $0.020 \mathrm{~m}$ to $0.014 \mathrm{~m}$; nor it can be attributed to the value of the passive thrust of the sloping soil: on estimating this thrust with a $\phi$ of $45^{\circ}$ instead of $40^{\circ}$, the displacement would be reduced only from $0.020 \mathrm{~m}$ to $0.018 \mathrm{~m}$.

The uplift wave force should increase the displacement, in that it is expected to reduce $R_{v}$ at the time instants of the IBWP on the upright section, even though this effect should not be important. In fact this effect should be much smaller with our foundation (Figure 8(a)) than with a simple foundation like that of Figure 8(b). In conclusion with Equations (15)-(17) we expect a small displacement of breakwater A of the order of a few centimeters, whereas the actual displacement was zero. We believe that this higher resistance of breakwater A is due to the effect of ground which is elastically deformed under an application of an impulsive breaking wave pressure (this topic was approached by [6]). However, the deformation of soil here would require a 3D model because the waves are short-crested; and this is beyond recent practice [4]. Moreover, it would be necessary to measure the wave force on the whole length of the breakwater, and not only on one section.

Equations (15)-(17) may be applied also to predict the displacement of a block on another block of breakwater B (of course in this case $R_{p}$ must be taken zero). With the time series data of $p_{w}(t)$ of the 9 five-minute records in which breakwater A collapsed we obtain the following result with $\mu=0.6, C_{i n}=2$, and assuming $R_{v}=P^{*}$ :

1) the displacement of block 1 with respect to block 2 is of $0.05 \mathrm{~m}$ as a result of 35 small slides;

2) the displacement of block 2 with respect to block 3 is of $0.04 \mathrm{~m}$ as a result of 46 small slides;

3) the displacement of block 3 with respect to block 4 is of $0.02 \mathrm{~m}$ as a result of 46 small slides.

These displacements obtained on neglecting the uplift force at the base of each block ( $R_{v}$ assumed to be equal to $P^{*}$ ) are shown in Figure 9(a). The displacements obtained on taking the uplift force into account are shown in Figure 9(b), wherein the situation becomes as follows:

1) the displacement of block 1 with respect to block 2 becomes of $0.49 \mathrm{~m}$ as a result of 63 small slides;

2) the displacement of block 2 with respect to block 3 becomes of $0.32 \mathrm{~m}$ as a result of 97 small slides;

3) the displacement of block 3 with respect to block 4 becomes of $0.17 \mathrm{~m}$ as a result of 86 small slides.

The uplift force is estimated with the usual linear scheme (see Figure 10). It is evident, from a comparison between Figure 9(b) and Figure 9(a), that a crucial role in the collapse of breakwater B was played by the uplift force at the base of each individual block. Of course from Figure 9(b) we may expect that blocks 1 and 2 fall; and this actually occurred.

\section{Conclusions}

The questionnaire [3] provides a most clear way to approach the problem of the danger of IBWP. However as Goda himself notes "it is advisable to resort to hydraulic model testing whenever there remains the suspicion of the generation of impulsive breaking wave pressure". According to the questionnaire, if the rubble mound is sufficiently small to be considered negligible, it should not be easy that IBWP are exerted by wind seas attacking nearly orthogonally.

Another reason for which there should have been little danger of IBWP was that the crest elevation of our breakwater was so small as to allow much overtopping: crest elevation between $1 / 5$ and less than $1 / 2$ of $H_{s 0}$.

Nevertheless, we recorded some well evident IBWP on breakwater A.

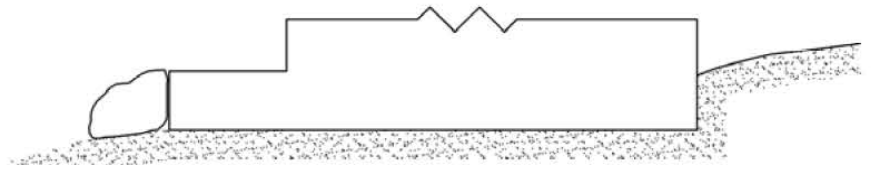

(a)

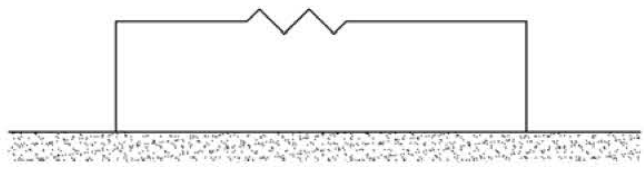

(b)

Figure 8. (a) Foundation of breakwaters A or B; (b) a simple foundation considered in our analysis. 

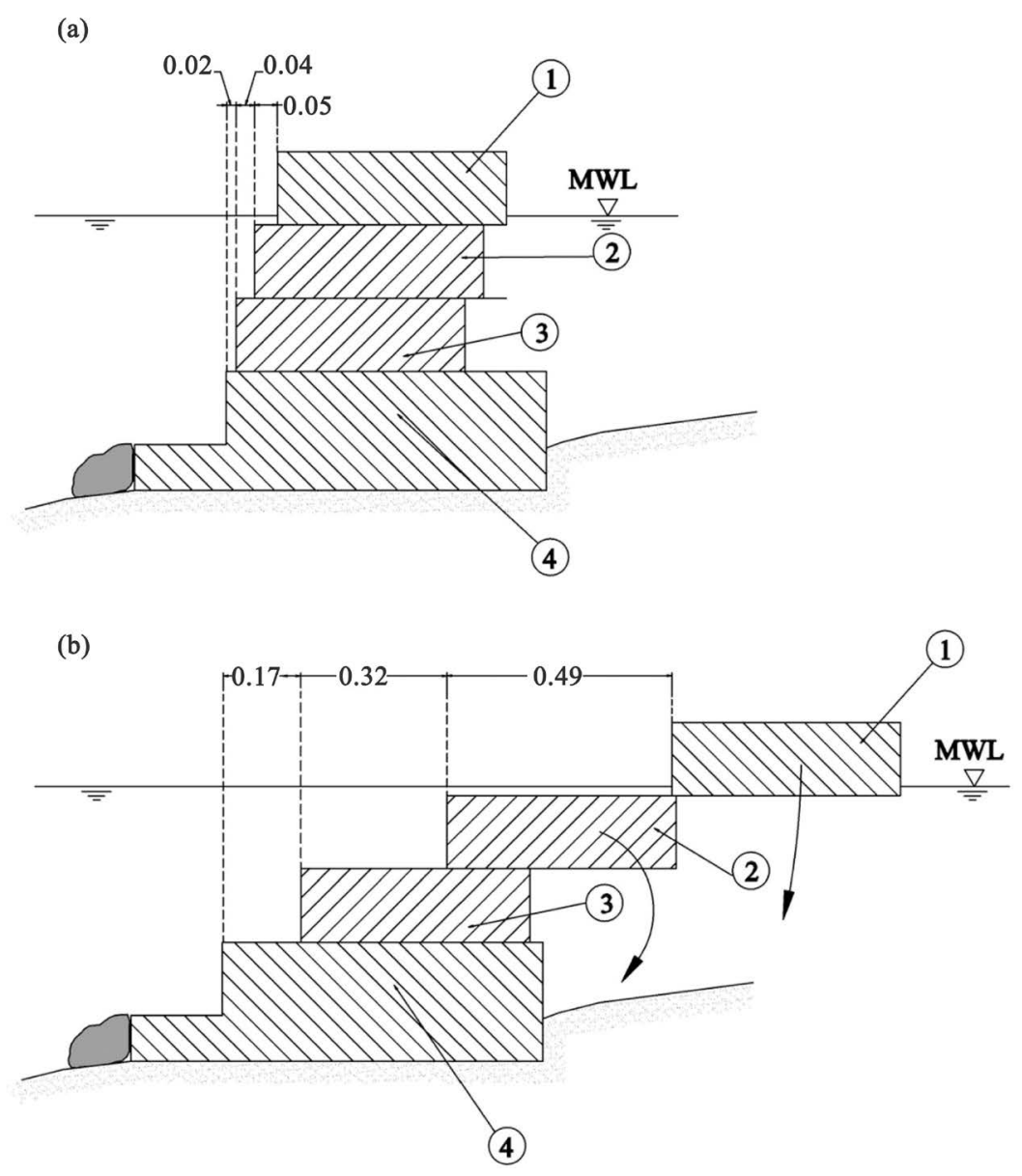

Figure 9. Estimated displacement of the blocks in the 45 minutes in which breakwater B was destroyed. The uplift force at the base of the blocks: (a) is neglected; (b) is taken into account.

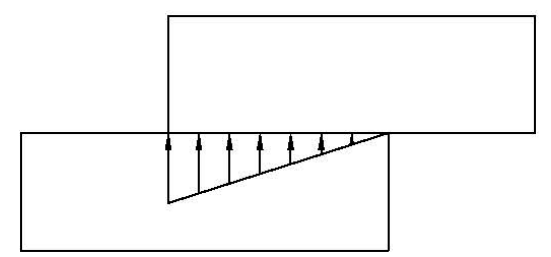

\section{Figure 10. Scheme of the uplift force at the base of a block.}

Because of the fact that:

1) the duration of IBWP was very small;

2) the effect of IBWP on the uplift force was probably negligible, due to the configuration of the foundation; the displacement of breakwater A with our 24 five-minute records of wind seas should have been within a few centimeters. The fact that no displacement was observed after the action of these wind seas could be explained as an effect of ground which was elastically deformed under an application of an impulsive breaking wave pressure.

Under essentially the same wind seas which were perfectly withstood by breakwater A, breakwater B rapidly collapsed. From our analysis based on Equations (15)-(17) with the time series data of the $p_{w}$ on the wall, we conclude that the uplift force at the base of each block was the primary cause of the collapse.

As explained in Section 3.7 of [1], the crucial requirement for a SSFE at some site is "to be reasonably sure that a sea state with some prescribed characteristics will occur after a short waiting time at this site”. For this SSFE the prescribed characteristics were: water depth $d_{n}$ at the breakwater (inclusive of the tide) between 0.55 
$\mathrm{m}$ and $0.65 \mathrm{~m}$; ( $d$ between $0.45 \mathrm{~m}$ and $0.55 \mathrm{~m}$ ); $H_{\mathrm{s} 0}$ between about $0.40 \mathrm{~m}$ and $0.50 \mathrm{~m}$; type of waves: wind seas $\left(\psi^{*}>0.60\right) ; H_{s 0} / L_{0}$ covering range Equation (18) of most interest. After 25 years of experiments in the sea of Reggio Calabria we know that we may obtain these conditions. A novelty with respect to the previous SSFEs was in the narrow window for the water depth: the amplitude of this window was smaller than the tide amplitude (this being about $0.15 \mathrm{~m}$ ). The conditions on $d_{n}, d$ and $H_{s 0}$ served to have a meaningful ratio $W / d$ as well as to have the breaking point of the progressive wave (in absence of the structure) being located only slightly in front of the breakwater.

We obtained many records of sea states with the prescribed characteristics in less than one month. This represents a step forward in the technique of SSFEs, since it is proved that, at least at some sites, these experiments can be performed even on structures of the surf zone.

\section{References}

[1] Boccotti, P. (2015) Wave Mechanics and Wave Loads on Marine Structures. Elsevier, Amsterdam.

[2] Bagnold, R.A. (1939) Interim Report on Wave-Pressure Research. Journal of the Institution of Civil Engineers, 12, 202-226. http://dx.doi.org/10.1680/ijoti.1939.14539

[3] Goda, Y. (2000) Random Seas and Design of Maritime Structures. World Scientific, Singapore. http://dx.doi.org/10.1142/3587

[4] Cuomo, G., Lupoi, G., Shimosako, K. and Takahashi, S. (2011) Dynamic Response of Composite Breakwaters under Breaking and Non-Breaking Wave Attack. Coastal Engineering, 58, 953-969. http://dx.doi.org/10.1016/j.coastaleng.2011.03.008

[5] Boccotti, P. (2000) Wave Mechanics for Ocean Engineering. Elsevier, Amsterdam.

[6] Goda, Y. (1994) Dynamic Response of Upright Breakwaters to Impulsive Breaking Wave Forces. Coastal Engineering, 22, 135-158. http://dx.doi.org/10.1016/0378-3839(94)90051-5 


\section{Appendix}

According to the questionnaire [3], if the rubble mound is sufficiently small to be considered negligible, and the steepness of the deepwater wave is greater than $0.03 /(\mathrm{Cd} \mathrm{Cr})$ there is little danger of IBWP. With this condition on wave steepness the danger of IBWP with wind seas, typically, should be little. (This is, unless there are some important diffraction and/or refraction phenomena so that the $\mathrm{Cd}$ and/or the $\mathrm{Cr}$ of the directional spectrum are largely smaller than 1). Here, please bear in mind that a typical range of values of the deepwater wave steepness of wind seas is

$$
0.040<H_{s 0} / L_{p 0}<0.056
$$

(this is obtained with the mean JONSWAP spectrum, and the Phillips parameter in $(0.01,0.02)$ ). Of course the range of the deepwater wave steepness of the largest waves in a wind sea will be even greater than that given by inequality 18. That is why it should not be easy to find IBWP on a breakwater like our breakwater which was attacked nearly orthogonally by wind seas.

\section{Notation}

The following symbols are used in this paper:

$a_{y}=y$-component of acceleration;

$C_{d}=$ diffraction coefficient;

$C_{i n}=$ inertia coefficient;

$C_{r}=$ refraction coefficient;

$d$ = water depth at the toe of the upright section;

$d_{n}=$ depth of the seabed at the breakwater;

$E=$ frequency spectrum;

$F$ = wave force on the upright section;

$f=$ frequency;

$g=$ acceleration of gravity;

$H_{s 0}=$ significant wave height on deep water;

$L_{0}=$ deepwater wave length relevant to wave period $T_{h}$

$M=$ breakwater mass;

$P^{*}=$ weight in still water;

$p_{w}=$ wave pressure;

$R_{p}=$ passive thrust of soil behind a breakwater;

$R_{v}=$ vertical reaction;

$s_{y}=y$-component of displacement;

$T=$ time lag;

$T_{1 / 3}=$ average of the wave periods of the largest $1 / 3$ waves in a sea state;

$T_{h}=$ period of the largest waves in a sea state;

$T_{p}=$ peak period in a sea state;

$t=$ time;

$v_{y}=y$-component of velocity;

$y=$ horizontal axis orthogonal to the breakwater;

$W=$ crest elevation of breakwater;

$\Delta t=$ sample interval;

$\phi=$ soil friction angle;

$\gamma=$ specific weight of water;

$\zeta=$ vertical axis with origin at the toe of the upright section;

$\mu=$ friction factor;

$\psi=$ autocovariance function;

$\psi^{*}=$ narrow bandedness parameter (= absolute value of ratio between the minimum and maximum of the autocovariance function). 